CLINICAL STUDY

\title{
Confirmatory testing in primary aldosteronism: extensive medication switching is not needed in all patients
}

\author{
Miroslav Solar $^{1}$, Eva Malirova ${ }^{2}$, Marek Ballon $^{1}$, Radek Pelouch ${ }^{1}$ and Jiri Ceral ${ }^{1}$ \\ Departments of ${ }^{1}$ Internal Medicine and ${ }^{2}$ Nuclear Medicine, Charles University Prague, University Hospital Hradec Kralove, Sokolska 581,50005 Hradec \\ Kralove, Czech Republic \\ (Correspondence should be addressed to J Ceral; Email: ceral@seznam.cz)
}

\begin{abstract}
Objective: Confirmatory testing of suspected primary aldosteronism (PA) requires an extensive medication switch that can be difficult for patients with severe complicated hypertension and/or refractory hypokalemia. For this reason, we investigated the effect of chronic antihypertensive medication on confirmatory testing results. To allow the results to be interpreted, the reproducibility of confirmatory testing was also evaluated.

Design and methods: The study enrolled 114 individuals with suspected PA who underwent two confirmatory tests. The patients were divided into two groups. In Group A, both tests were performed on the guidelines-recommended therapy, i.e. not interfering with the renin-angiotensin-aldosterone system. In Group B, the first test was performed on chronic therapy with the exclusion of thiazides, loop diuretics, and aldosterone antagonists; and the second test was performed on guidelines-recommended therapy. Saline infusion, preceded by oral sodium loading, was used to suppress aldosterone secretion. Results: Agreement in the interpretation of the two confirmatory tests was observed in 84 and $66 \%$ of patients in Groups A and B respectively. For all 20 individuals in Group A who ever had end-test serum aldosterone levels $\geq 240 \mathrm{pmol} / \mathrm{l}$, aldosterone was concordantly nonsuppressible during the other test. Similarly, for all 16 individuals in Group B who had end-test serum aldosterone levels $\geq 240 \mathrm{pmol} / \mathrm{l}$ on modified chronic therapy, aldosterone remained nonsuppressible with guidelines-recommended therapy. Conclusion: Confirmatory testing performed while the patient is on chronic therapy without diuretics and aldosterone antagonists can confirm the diagnosis of PA, provided serum aldosterone remains markedly elevated at the end of saline infusion.
\end{abstract}

European Journal of Endocrinology 166 679-686

\section{Introduction}

Primary aldosteronism (PA) is not an infrequent form of secondary arterial hypertension. The cardiovascular consequences of this disorder go beyond blood pressure elevation $(1,2)$. It is important to identify PA cases as affected individuals can benefit from specific medical or surgical treatment. The PA diagnostic algorithm consists of screening, confirmation, and subtype differentiation.

The main obstacle when diagnosing PA is the need for a medication switch before confirmatory testing. According to the current guidelines (3), only drugs with minimal or no effects on the renin-angiotensinaldosterone system (RAAS) can be administered before and during the confirmatory testing.

However, the medication change as suggested by the guidelines carries a risk of uncontrolled hypertension and severe hypokalemia. For this reason, confirmatory testing is often contraindicated in individuals with severe complicated hypertension or a history of significant hypokalemia.
Conversely, the effects of chronic antihypertensive therapy on confirmatory testing are not completely understood, and it is not known whether an extensive medication change is necessary in all patients referred for confirmatory testing.

These facts inspired us to investigate this aspect of the PA diagnostic process. To interpret the effects of chronic therapy on confirmatory testing, we also evaluated the reproducibility of confirmatory testing performed under the recommended conditions.

Oral sodium loading with subsequent saline infusion was used to suppress aldosterone secretion. This simple procedure can be performed on an outpatient basis.

\section{Subjects and methods}

Patients with suspected PA who were referred for confirmatory testing on the basis of screening results were prospectively enrolled. The study was approved by the Local Ethics Committee, and all participants 
provided written informed consent. All enrolled individuals were examined according to the protocol described below.

\section{PA screening}

The aldosterone-to-renin ratio (ARR) was used to screen patients with possible PA. Before ARR testing, no changes in the patients' medications were required except for withdrawal from any aldosterone antagonist for at least 2 months. These drugs were not allowed until the PA diagnostic procedures were completed.

Blood sampling for ARR was always performed in the morning (between 0700 and $1000 \mathrm{~h}$ ) when the patients had been in the upright position for at least $30 \mathrm{~min}$. To calculate ARR, both serum aldosterone and plasma renin concentrations were expressed in nanograms per liter. On the basis of our observations in healthy volunteers, ARRs $>20$ were considered abnormal (4).

Referral for confirmatory testing resulted mainly from repeatedly elevated ARR in screened patients. However, testing was also indicated for selected hypertensive individuals who presented with otherwise unexplained hypokalemia or an adrenal adenoma.

\section{Confirmatory testing}

Two confirmatory tests were performed for all enrolled patients. The patients were divided into two groups (A and $\mathrm{B}$ ) that differed in the medication the patients were given before testing. The patients were allocated into the study groups consecutively, i.e. after enrolment in one group was completed, enrolment in the other group was initiated. The investigators had no influence on the allocation of the patients into the respective groups.

\section{Group A}

For patients in Group A, both confirmatory tests were performed under identical RAAS-neutral conditions, i.e. excluding any antihypertensive therapy interfering with RAAS. These drugs had to be stopped at least 2 weeks before the first test. When the risks of uncontrolled blood pressure were considered high, the patients were given doxazosin and/or verapamil. The suggested period between the two tests was 2 weeks. No changes in the antihypertensive medications were allowed during the period between tests. All patients who required any antihypertensive therapy adjustment before the second suppression test were excluded from the final analysis.

\section{Group B}

For patients in Group B, the first confirmatory test was performed under minimally modified chronic antihypertensive therapy. Excluding aldosterone antagonists that were not allowed at any point in the diagnostic process, thiazides and loop diuretics had to be stopped at least 2 weeks before the test. In patients with a history of severe hypokalemia, amiloride was permitted at a dose not exceeding $15 \mathrm{mg} /$ day.

The second confirmatory test was performed with the exclusion of any antihypertensive therapy potentially interfering with the RAAS. These drugs had to be discontinued at least 2 weeks before testing. The only antihypertensive medications allowed were doxazosin and/or verapamil. The results of the second confirmatory test were used as the reference for clinical decision-making.

In both study groups, oral potassium supplementation was administered as needed at any time during the confirmatory testing.

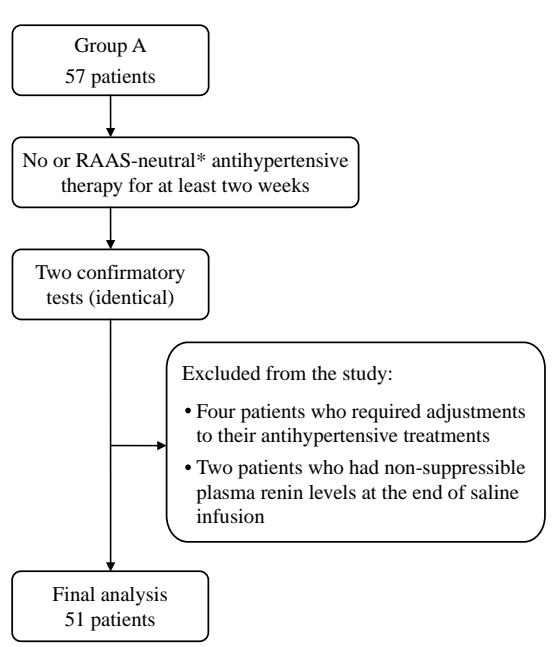

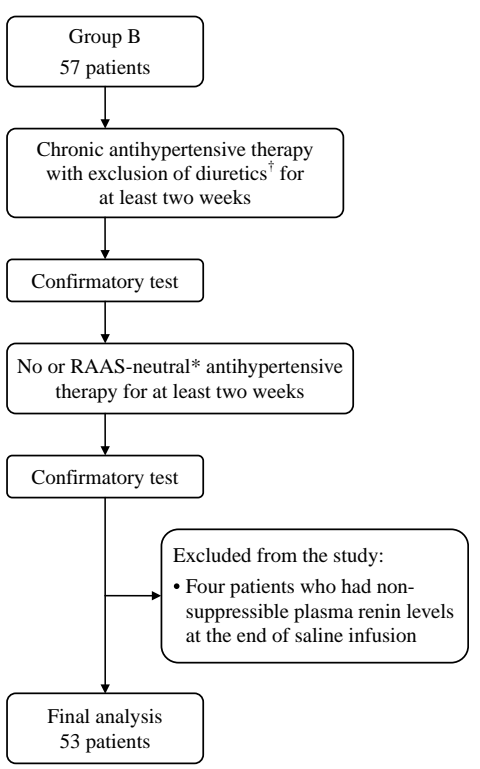

Figure 1 Study protocol. Flowchart describes the study protocol in brief, including the study procedures and the patients excluded from the analysis. ${ }^{*}$ Denotes a therapy with no or minimal effect on the RAAS, only doxazosin and/or verapamil were allowed. ${ }^{\dagger}$ Only amiloride was permitted at a dose not exceeding $15 \mathrm{mg} /$ day. 
All confirmatory tests in the study were performed according to the protocol that is routinely used in our center.

Oral sodium loading preceded the i.v. administration of normal saline, as a short-lasting infusion itself might not be sufficient to suppress renin and aldosterone secretion.

The patients were advised to enhance their oral salt intake after adjusting their medication before testing. Three days before the saline infusion was administered, oral salt intake was further increased by at least $6 \mathrm{~g} /$ day. The day before the saline infusion, a 24-h urine sample was collected to measure urinary sodium excretion.

Saline was always infused in the morning. After $2 \mathrm{~h}$ of bed rest, $2 \mathrm{l}$ of normal saline was infused over a 4-h period. The patients remained in the supine position until the end of the infusion, when blood samples were taken for the estimations of plasma renin and serum aldosterone.

The criteria for interpreting confirmatory tests were based on our observations in healthy volunteers (4) as follows: patients who had plasma active renin levels $\geq 7 \mathrm{ng} / \mathrm{l}$ at the end of any confirmatory test performed during RAAS-neutral therapy were excluded from the final analysis. The exclusion limit reflects the 97.5 percentile of the values observed in healthy volunteers who underwent the same diagnostic protocol. Serum aldosterone was considered suppressible at levels $\leq 100 \mathrm{pmol} / \mathrm{l}$ at the end of the saline infusion. This cutoff is routinely used in our center. It was set arbitrarily between the 97.5 percentile of the values of healthy volunteers (60 pmol/l) and the lowest cutoff mentioned in the current guidelines (139 pmol/l).

\section{Adrenal venous sampling}

Adrenal venous sampling (AVS) was offered to all patients who had nonsuppressible serum aldosterone at the end of any suppression test performed during RAASneutral therapy.

The AVS protocol used in our center has been described in detail elsewhere (5). In brief, a continuous cosyntropin infusion was given during the procedure. The adrenal veins were sequentially cannulated. Adrenal samples were considered adequate if the cortisol concentration was at least fivefold greater than that of the inferior vena cava. Adrenalectomy was recommended to patients whose cortisol-corrected aldosterone concentration from the affected gland was at least fourfold higher than that of the contralateral side.

\section{Laboratory measurement}

For all collected blood samples, the material was processed and frozen within $1 \mathrm{~h}$ after the blood was taken. Plasma renin measurements were performed using the Renin III Generation radioimmunometric assay (CIS Bio International, Gif sur Yvette Cedex, France). The method's detection range was 2.7$340 \mathrm{ng} / \mathrm{l}$. When the estimated renin concentration was below the assay's lower limit of detection, the renin concentration was considered the lowest detectable value, i.e. $2.7 \mathrm{ng} / \mathrm{l}$. The observed intra-assay coefficients of variation (CV values) were 9.5 and $3.2 \%$ for renin concentrations of 7.6 and $347.3 \mathrm{ng} / \mathrm{l}$ respectively. The observed interassay $\mathrm{CV}$ values were 11.9 and $5.2 \%$ for renin concentrations of 24.6 and $281 \mathrm{ng} / \mathrm{l}$ respectively.

Serum aldosterone concentrations were measured using a commercially available RIA (Coat-A-Count aldosterone; Siemens/DPC, Los Angeles, CA, USA). The assay's range was $30-3880 \mathrm{pmol} / \mathrm{l}$. When the estimated aldosterone concentrations were below the lower detection limit, the samples were considered to have the lowest detectable serum aldosterone concentration, i.e. $30 \mathrm{pmol} / \mathrm{l}$. The observed intra-assay $\mathrm{CV}$ values were 10.2 and $4.31 \%$ for aldosterone concentrations of 160 and $550 \mathrm{pmol} / \mathrm{l}$ respectively. The observed interassay CV values were 10.3 and $7.6 \%$ for aldosterone concentrations of 155 and $1560 \mathrm{pmol} / \mathrm{l}$ respectively.

To calculate ARRs, both aldosterone and renin concentrations were expressed in nanograms per liter. To convert aldosterone concentration to mass units, a coefficient of $0.361 \mathrm{ng} / \mathrm{pmol}$ was used.

\section{Statistical analysis}

MedCalc Software (version 11.6) was used for the statistical analysis of the acquired data.

Table 1 Patients' principle characteristics. The table shows the data of patients who were enrolled in the analysis. Unless otherwise stated, the data are expressed as medians (ranges). Group A patients underwent two identical confirmatory tests under RAASneutral therapy, only doxazosin and/or verapamil were allowed. Group B patients underwent two confirmatory tests: the first during modified chronic antihypertensive therapy and the second during RAAS-neutral therapy, only doxazosin and/or verapamil were allowed.

\begin{tabular}{|c|c|c|}
\hline & Group A & Group B \\
\hline $\begin{array}{l}\text { No. of patients } \\
\text { (women) }\end{array}$ & $51(8)$ & $53(10)$ \\
\hline Age (years) & $47(21-68)$ & $57(35-72)$ \\
\hline $\begin{array}{l}\text { Systolic BP } \\
(\mathrm{mmHg})^{\mathrm{a}}\end{array}$ & $142(100-196)$ & $138(110-220)$ \\
\hline $\begin{array}{l}\text { Diastolic BP } \\
(\mathrm{mmHg})^{\mathrm{a}}\end{array}$ & $86(64-116)$ & $82(54-118)$ \\
\hline $\begin{array}{l}\text { No. of antihypertensive } \\
\text { drugs }^{a}\end{array}$ & $4(0-7)$ & $4(1-6)$ \\
\hline Aldosterone-to-renin ratio a,b & $66.9(16.3-176.5)$ & $77.5(18.9-162.8)$ \\
\hline
\end{tabular}

aData obtained during the screening for primary aldosteronism.

${ }^{b}$ To calculate the aldosterone-to-renin ratio, both aldosterone and renin were expressed in nanograms per liter. 
Table 2 Antihypertensive medications given during confirmatory tests performed after excluding drugs that interfere with the RAAS. The data are expressed as numbers of patients or medians (ranges). Group A patients underwent two identical confirmatory tests under RAAS-neutral therapy conditions, only doxazosin and/or verapamil were allowed. Group B patients underwent two confirmatory tests: the first with modified chronic antihypertensive therapy and the second with RAAS-neutral therapy, only doxazosin and/or verapamil were allowed.

\begin{tabular}{lccccc}
\hline & \multicolumn{2}{c}{ Group A (51 patients) } & & \multicolumn{2}{c}{ Group B (53 patients) } \\
\cline { 2 - 3 } & $\begin{array}{c}\text { Number of } \\
\text { patients }\end{array}$ & $\begin{array}{c}\text { Daily } \\
\text { dose }(\mathrm{mg})\end{array}$ & & $\begin{array}{c}\text { Number of } \\
\text { patients }\end{array}$ & $\begin{array}{c}\text { Daily } \\
\text { dose }(\mathrm{mg})\end{array}$ \\
\hline No therapy & 5 & & & 9 & \\
Verapamil & 46 & $240(120-480)$ & & 44 & $240(120-480)$ \\
Doxazosin & 46 & $4(1-16)$ & & 37 & $8(2-16)$ \\
\hline
\end{tabular}

\section{Results}

The study consecutively enrolled 114 patients with suspected PA. The patients were divided into two groups: Groups A and B. All of the patients were examined according to the study protocol (Fig. 1).

\section{Group A}

Group A included 57 patients, all of whom underwent two confirmatory tests under RAAS-neutral therapy. Six individuals were excluded from the final analysis: in two patients, plasma renin remained unsuppressed after one of the two tests, and in four patients, the verapamil and/or doxazosin dose was modified after the first test. The reasons for these medication changes were side effects and/or inadequate blood pressure control.

The data of the remaining 51 patients were included in the analysis. Patients' characteristics are shown in Table 1 . The antihypertensive medications administered during both tests are summarized in Table 2 .

Figure 2A compares the serum aldosterone concentrations at the end of both confirmatory tests performed in Group A patients. The difference in aldosterone concentrations ranged from 0 to $350 \mathrm{pmol} / \mathrm{l}$ (median: $50 \mathrm{pmol} / \mathrm{l})$.

Detailed results of both confirmatory tests in Group A patients are displayed in Tables 3 and 4. Overall, agreement in the interpretation of the two tests was noted in $43(84 \%)$ patients. The data from the eight patients who exhibited discordant results are shown in more detail in Table 5.

All 20 patients who had serum aldosterone concentrations $\geq 240 \mathrm{pmol} / \mathrm{l}$ at the end of either confirmatory test exhibited aldosterone nonsuppressibility at the end of the other test.

AVS was performed in 31 patients in Group A. Aldosterone secretion lateralization was observed in 15 individuals. All patients with proven aldosterone secretion lateralization had consistently nonsuppressible aldosterone at the end of both tests. None of the five patients who had discordant confirmatory test results and underwent AVS exhibited evidence of aldosterone secretion lateralization.

\section{Group B}

Fifty-seven patients with suspected PA were enrolled in Group B. All were examined according to the study protocol. Four individuals were excluded because of high plasma renin at the end of the second confirmatory test performed during RAAS-neutral therapy. The data of 53 patients were included in the analysis. The principal characteristics of these patients are shown in Table 1 . The antihypertensive medications given before both tests are summarized in Tables 2 and 6 .

Figure 2B compares the serum aldosterone concentrations at the end of both tests. The difference in aldosterone concentrations ranged from 0 to $360 \mathrm{pmol} / \mathrm{l}$ (median: $70 \mathrm{pmol} / \mathrm{l}$ ).
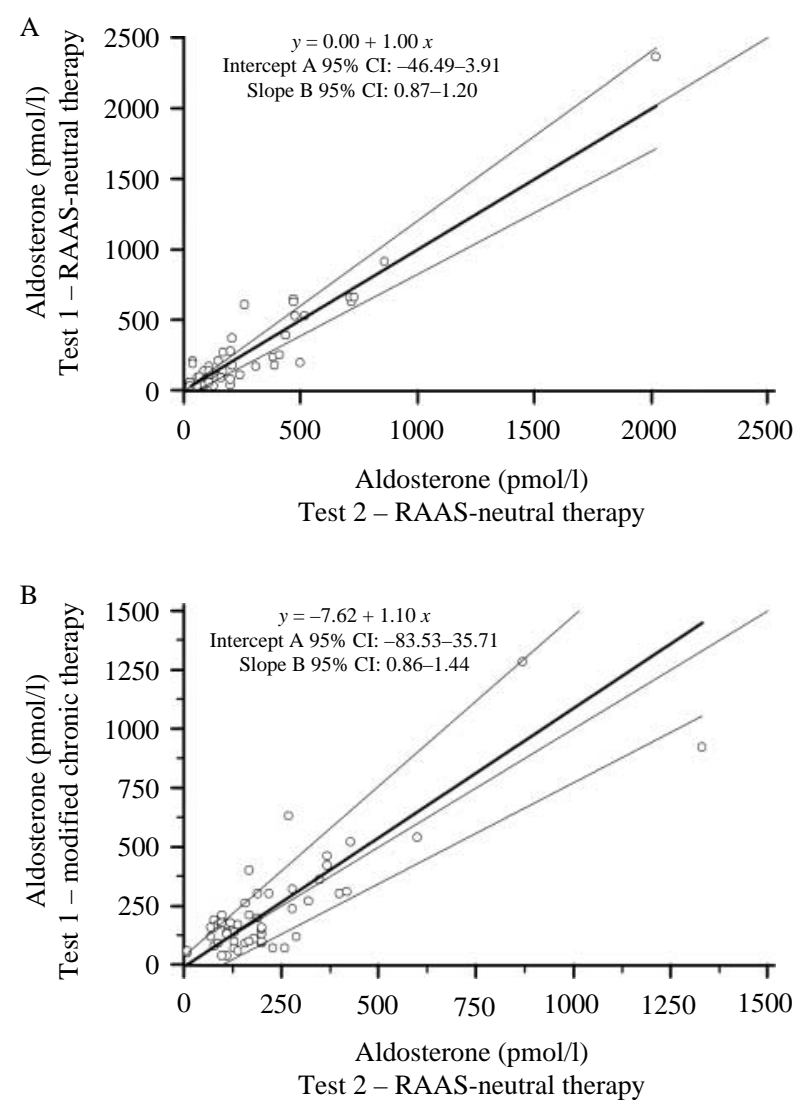

Figure 2 Comparison of serum aldosterone at the end of the confirmatory tests. This graph compares the end-test serum aldosterone (open circle) in Groups A (A) and B (B). PassingBablok regression analysis was used to analyze the differences between the compared confirmatory tests. In both study groups, wide $95 \%$ confidence intervals $(\mathrm{Cl})$ describing the regression line indicate only moderate agreement in the main results of the compared confirmatory tests. Bold lines indicate regression lines; grey lines indicate $95 \% \mathrm{Cl}$; and dotted lines indicate identity lines. 
Table 3 Confirmatory testing results. The data are expressed as medians and ranges. Group A patients underwent two identical confirmatory tests under RAAS-neutral therapy conditions. Group B patients underwent two confirmatory tests: the first with modified chronic antihypertensive therapy and the second with RAAS-neutral therapy.

\begin{tabular}{|c|c|c|c|c|}
\hline & \multicolumn{2}{|c|}{ Group A (51 patients) } & \multicolumn{2}{|c|}{ Group B (53 patients) } \\
\hline & Test $1^{a, b}$ & Test $2^{\mathrm{a}, \mathrm{b}}$ & Test $1^{\mathrm{c}}$ & Test $2^{\mathrm{a}}$ \\
\hline Aldosterone-to-renin ratio ${ }^{\mathrm{d}, \mathrm{e}}$ & $45.7(0.7-204.5)$ & $47.0(1.4-160.4)$ & $61(14-896)$ & $62(11-564)$ \\
\hline Serum potassium level $(\mathrm{mmol} /)^{\dagger}$ & $3.7(2.7-4.6)$ & $3.7(2.9-4.7)$ & $3.9(2.7-4.8)$ & $3.8(2.6-4.7)$ \\
\hline Urinary sodium excretion $(\mathrm{mmol} / 24 \mathrm{~h})^{\mathrm{f}}$ & $368(124-814)$ & $358(142-721)$ & $405(60-776)$ & $385(90-704)$ \\
\hline Plasma active renin after $2 \mathrm{~h}$ of bed rest (ng/l) & $2.7(2.7-10.8)$ & $2.7(2.7-7.4)$ & $2.7(2.7-38.8)$ & $2.7(2.7-43.2)$ \\
\hline Serum aldosterone after $2 \mathrm{~h}$ of bed rest $(\mathrm{pmol} / \mathrm{l})$ & $100(30-1900)$ & $160(40-1880)$ & $250(50-1780)$ & $255(50-1230)$ \\
\hline Plasma active renin at the end of saline infusion (ng/l) & $2.7(2.7-6.9)$ & $2.7(2.7-5.4)$ & $2.7(2.7-7.9)$ & $2.7(2.7-5.1)$ \\
\hline Serum aldosterone at the end of saline infusion $(\mathrm{pmol} / \mathrm{l})$ & $140(30-2400)$ & $160(30-2020)$ & $165(40-1280)$ & $165(30-1330)$ \\
\hline Systolic blood pressure $(\mathrm{mmHg})^{\mathrm{g}}$ & $150(120-192)$ & $158(116-196)$ & $150(118-220)$ & $164(115-218)$ \\
\hline Diastolic blood pressure $(\mathrm{mmHg})^{\mathrm{g}}$ & $92(70-118)$ & $94(70-122)$ & $90(70-120)$ & $95(70-110)$ \\
\hline
\end{tabular}

${ }^{a}$ Confirmatory tests performed under RAAS-neutral therapy, only doxazosin and/or verapamil were allowed.

${ }^{\mathrm{b} C o n f i r m a t o r y}$ tests performed with identical dosing of doxazosin and/or verapamil.

${ }^{c}$ Confirmatory tests performed under modified chronic antihypertensive therapy conditions, aldosterone antagonists and diuretics were withdrawn before testing.

${ }^{\mathrm{d} B l o o d}$ sampling was performed after oral sodium loading before the saline infusion was given.

${ }^{\mathrm{e}}$ To calculate the aldosterone-to-renin ratio, both aldosterone and renin were expressed in nanograms per liter.

${ }^{\dagger} A$ 24-h urine sample was collected the day before the saline infusion was administered.

${ }^{g}$ Blood pressure measurement after saline infusion.

The detailed data from both tests administered to Group B patients are summarized in Tables 3 and 7. Consonant interpretations of confirmatory tests were noted in $35(66 \%)$ patients, and discordant results were found in $18(34 \%)$ patients.

We have not identified any specific type of chronic antihypertensive medication associated more frequently with discordant results in the compared confirmatory tests.

Concerning amiloride administration, discordant results were observed in four $(20 \%)$ of 20 patients who were given this drug as part of the modified chronic therapy provided during the first test.

All 16 individuals who had serum aldosterone levels $\geq 240 \mathrm{pmol} / \mathrm{l}$ on modified chronic therapy end of testing exhibited consonant results when the test was repeated under RAAS-neutral therapy.

On the basis of the results of the second confirmatory test, 39 individuals underwent AVS. Aldosterone secretion lateralization was observed in 14 patients, three of these patients exhibited aldosterone suppression during the confirmatory test performed under modified chronic antihypertensive therapy conditions.

Table 4 The interpretation of confirmatory tests in Group A patients. The table compares the interpretation of two confirmatory tests in Group A patients. Both tests were performed under identical conditions on RAAS-neutral therapy. The data are expressed as the numbers of patients.

\begin{tabular}{cccc}
\hline & Serum aldosterone \\
at the end of saline & \multicolumn{2}{c}{ Test 1 } \\
\cline { 3 - 4 } infusion & $\begin{array}{c}\text { Suppressible } \\
(\leq 100 \mathrm{pmol} / \mathrm{l})\end{array}$ & $\begin{array}{c}\text { Nonsuppressible } \\
(>100 \mathrm{pmol} / \mathrm{l})\end{array}$ \\
\hline Test 2 & $\begin{array}{c}\text { Suppressible } \\
(\leq 100 \mathrm{pmol} / \mathrm{l}) \\
\text { Nonsuppressible } \\
(>100 \mathrm{pmol} / \mathrm{l})\end{array}$ & 15 & 3 \\
\hline
\end{tabular}

\section{Hypokalemia}

Serum potassium was measured after oral sodium loading before the saline infusion was given. Hypokalemia, defined as a potassium level $<3.5 \mathrm{mmol} / \mathrm{l}$, was observed in $24(23 \%)$ patients. All but one of these patients received potassium supplementation, with a mean dose of $46( \pm 18) \mathrm{mmol} /$ day. No patient with hypokalemia achieved aldosterone suppression at the end of saline infusion.

\section{Side effects}

We did not encounter any major complications that required acute hospital admission in any of the enrolled patients.

Peripheral edema was observed in seven patients and was more commonly associated with therapy limited to verapamil and/or doxazosin. An episode of atrial fibrillation developed in one patient on doxazosin and verapamil; hypokalemia was not detected. Dyspnea of effort was reported by three patients, and two patients reported headaches; neither complaint was related to any specific therapy.

\section{Discussion}

Our study assessed the clinical value of confirmatory testing performed under modified chronic antihypertensive therapy with the exclusion of thiazides, loop diuretics, and aldosterone antagonists. To interpret the results, the study protocol also evaluated the reproducibility of confirmatory testing performed under RAASneutral antihypertensive therapy conditions. 
Table 5 The analysis of data from Group A patients whose confirmatory test results were discordant. Both tests were performed under the same RAAS-neutral therapy conditions.

\begin{tabular}{|c|c|c|c|c|c|c|c|c|c|c|}
\hline \multirow[b]{2}{*}{$n$} & \multirow[b]{2}{*}{$\begin{array}{l}\text { Days off } \\
\text { chronic } \\
\text { therapy }^{\mathrm{a}}\end{array}$} & \multicolumn{4}{|c|}{ Test 1} & \multicolumn{4}{|c|}{ Test 2} & \multirow[b]{2}{*}{$\begin{array}{c}\text { AVS/ } \\
\text { lateralization }\end{array}$} \\
\hline & & $\begin{array}{c}\text { Urinary } \\
\text { sodium } \\
(\text { mmol/day })^{\mathrm{b}}\end{array}$ & $\begin{array}{c}\text { Serum } \\
\text { potassium } \\
(\mathrm{mmol} / /)^{\mathrm{c}}\end{array}$ & $\begin{array}{l}\text { Plasma } \\
\text { renin } \\
\left(\mathrm{ng} / \mathrm{l}^{\mathrm{d}}\right.\end{array}$ & $\begin{array}{l}\text { Serum } \\
\text { aldosterone } \\
(\mathrm{pmol} / \mathrm{l})^{\mathrm{d}}\end{array}$ & $\begin{array}{c}\text { Urinary } \\
\text { sodium } \\
(\mathrm{mmol} / \text { day })^{\mathrm{b}}\end{array}$ & $\begin{array}{c}\text { Serum } \\
\text { potassium } \\
(\mathrm{mmol} / \mathrm{l})^{\mathrm{c}}\end{array}$ & $\begin{array}{l}\text { Plasma } \\
\text { renin } \\
(\mathrm{ng} /)^{\mathrm{d}}\end{array}$ & $\begin{array}{c}\text { Serum } \\
\text { aldosterone } \\
(\text { pmol/l/l) }\end{array}$ & \\
\hline 1 & 43 & 506 & 3.7 & 2.7 & 30 & 503 & 3.6 & 2.7 & 130 & Yes/no \\
\hline 2 & 18 & 457 & 3.8 & 5.9 & 210 & 636 & 3.6 & 2.7 & 40 & Yes/no \\
\hline 3 & 22 & 161 & 3.7 & 3 & 190 & 142 & 4.2 & 2.7 & 40 & No/- \\
\hline 4 & 15 & 376 & 3.9 & 2.7 & 40 & 153 & 4.2 & 2.7 & 200 & No/- \\
\hline 5 & 48 & 814 & 3.6 & 2.7 & 80 & 436 & 3.9 & 2.7 & 200 & Yes/no \\
\hline 6 & 19 & 359 & 4.5 & 2.7 & 60 & 300 & 4.2 & 2.7 & 110 & No/- \\
\hline 7 & 31 & 586 & 4.2 & 4.6 & 140 & 502 & 3.6 & 3.2 & 90 & Yes/no \\
\hline 8 & 132 & 651 & 4.5 & 2.7 & 90 & 719 & 4.3 & 2.7 & 160 & Yes/no \\
\hline
\end{tabular}

$n$, number of patients; -, indicates not applicable.

${ }^{a}$ Number of days that chronic antihypertensive therapy with a potential influence on RAAS had been stopped before the first confirmatory test was performed. The only drugs allowed during this period were doxazosin and verapamil.

${ }^{\mathrm{b}} \mathrm{A}$ 24-h urine sample was collected after oral sodium loading the day before the saline infusion was given.

${ }^{\mathrm{C}}$ Blood sampling was performed after 3 days of oral sodium loading before the saline infusion was given.

${ }^{\mathrm{d} B}$ Blood samples were taken at the end of saline infusion. AVS denotes successful adrenal venous sampling. Lateralization denotes the lateralization of aldosterone secretion from one adrenal gland.

\section{The reproducibility of the confirmatory testing performed with RAAS-neutral antihypertensive therapy}

Consonant results for two identical confirmatory tests were observed in a majority of examined patients; however, the number of patients with discordant results was not negligible. The only definite predictor of concordantly positive results was the marked elevation of serum aldosterone at the end of saline infusion.

We cannot provide any definite explanation for the observed discrepancies. Some of the discordant findings may result from imperfect renin suppression (in patients 2 and 7, Table 5) or insufficient oral sodium loading (patient 4, Table 5).

We suppose that autonomous aldosterone secretion may be excluded in all patients who ever had serum aldosterone suppression levels $<60 \mathrm{pmol} / \mathrm{l}$, i.e. below the 97.5 percentile of values obtained from healthy volunteers who underwent identical confirmatory testing (4).

The discrepant interpretations of the compared tests cannot be attributed solely to the inherent imprecision of laboratory methods. As is apparent from the data presented in Table 5, the expected inaccuracies of hormonal estimations were usually below the observed differences in aldosterone concentrations.

We do not assume that previous chronic medical therapy influenced the results. In all patients whose data are presented in Table 5, the periods during which they were not taking chronic medication were sufficient for the complete elimination of previously administered antihypertensive medications.

We did not encounter hypokalemia 'masking' an autonomous aldosterone secretion; the instances of hypokalemia in our study resulted from excessive aldosterone overproduction.

\section{The effect of chronic antihypertensive medication on the results of confirmatory testing}

In one-third of Group B patients, there were discrepancies in the interpretation of the two confirmatory tests. Modified chronic medication was associated with aldosterone suppressibility, even in a few of the patients who were eventually found to have aldosterone secretion lateralization.

Conversely, the highest end of the serum aldosterone test with modified chronic therapy uniformly predicted aldosterone nonsuppressibility when the test was repeated under RAAS-neutral therapy. It appears that severely excessive aldosterone overproduction may not be effectively suppressed by modified chronic antihypertensive medication.

It is also important to note that amiloride administration did not influence the confirmatory test results in the majority of patients who received this drug as a part

Table 6 The modified chronic antihypertensive therapy administered to Group B patients during the first confirmatory test. The data are expressed as numbers of patients (percentages)

Beta blockers $45(85 \%)$

Angiotensin-converting enzyme inhibitors $35(66 \%)$ Angiotensin receptor blockers

$8(15 \%)$

Calcium channel blockers

$41(77 \%)$

Alpha blockers

Centrally acting drugs

$31(58 \%)$

Amiloride ${ }^{a}$

$8(15 \%)$

$20(38 \%)$

${ }^{\mathrm{a}}$ The mean dose of amiloride was $9( \pm 3.8) \mathrm{mg}$. 
Table 7 The interpretation of confirmatory tests in Group B patients. The table compares the interpretation of two confirmatory tests in Group B patients. The data are expressed as the numbers of patients.

\begin{tabular}{llcc}
\hline & & $\begin{array}{c}\text { Test during modified chronic } \\
\text { antihypertensive therapy }\end{array}$ \\
\cline { 3 - 4 } & $\begin{array}{c}\text { Serum aldosterone } \\
\text { at the end of saline } \\
\text { infusion }\end{array}$ & $\begin{array}{c}\text { Suppressible } \\
(\leq 100 \mathrm{pmol} / \mathrm{l})\end{array}$ & $\begin{array}{c}\text { Nonsuppressible } \\
(>100 \mathrm{pmol} / \mathrm{l})\end{array}$ \\
\hline $\begin{array}{l}\text { Test during } \\
\text { RAAS-neutral } \\
\text { therapy }\end{array}$ & $\begin{array}{c}\text { Suppressible } \\
(\leq 100 \mathrm{pmol} / \mathrm{l})\end{array}$ & 5 & 11 \\
\hline & $\begin{array}{c}\text { Nonsuppressible } \\
(>100 \mathrm{pmol} / \mathrm{l})\end{array}$ & 7 & 30 \\
\hline
\end{tabular}

of their modified chronic therapy. This observation may be important for patients with severe hypokalemia, for whom there are concerns about the safety of performing confirmatory testing according to the therapy recommended by the guidelines.

\section{Study limitations}

The main limitation of our study is the unclear definition of aldosterone suppressibility. There is no gold standard for reliably confirming autonomous aldosterone production. Our study, as well as other reports $(6,7,8,9,10)$, used an arbitrary criterion to define aldosterone suppressibility. Despite the fact that our cutoff for defining PA was rather low, we cannot be sure that it was sufficient to identify all individuals with autonomous aldosterone secretion.

We are aware that the addition of one more confirmatory test to the study protocol would further improve our understanding of the clinical question studied. However, the extension of the study procedures was considered highly impractical from the patients' point of view.

Finally, our observations cannot be automatically extrapolated as the reported data are closely related to the protocol and the hormonal assays used. Significant differences among kits from different manufacturers exist (11).

\section{Conclusion}

Our data suggest that an extensive medication switch is not necessary for all patients who are referred for confirmatory testing for suspected PA. Chronic therapy with the exclusion of aldosterone antagonists, thiazides, and loop diuretics may offer an alternative to RAASneutral therapy in patients with severe, complicated hypertension and/or refractory hypokalemia.

The results of confirmatory testing performed with modified chronic therapy are valid only when the serum aldosterone is markedly elevated at the end of saline infusion. In the remaining cases, tests conducted under modified chronic therapy conditions must be considered inconclusive.

Another important finding of our study is the limited reproducibility of confirmatory testing under RAASneutral therapy conditions. The confirmatory test is worth repeating unless the serum aldosterone concentration is markedly high or markedly low at the end of the test. The aim of repeated testing is to find patients who are able to suppress serum aldosterone to very low levels, which makes a PA diagnosis improbable. The need for AVS can be decreased by this approach.

\section{Declaration of interest}

The authors declare that there is no conflict of interest that could be perceived as prejudicing the impartiality of the research reported.

\section{Funding}

This work was supported by research projects of the Czech Ministry of Health (grant number MZO00179906) and Czech Ministry of Education (grant number MSM0021620817).

\section{References}

1 Milliez P, Girerd X, Plouin PF, Blacher J, Safar ME \& Mourad JJ. Evidence for an increased rate of cardiovascular events in patients with primary aldosteronism. Journal of the American College of Cardiology 200545 1243-1248. (doi:10.1016/j.jacc. 2005.01.015)

2 Sechi LA, Novello M, Lapenna R, Baroselli S, Nadalini E, Colussi GL \& Catena C. Long-term renal outcomes in patients with primary aldosteronism. Journal of the American Medical Association 2006 295 2638-2645. (doi:10.1001/jama.295.22.2638)

3 Funder JW, Carey RM, Fardella C, Gomez-Sanchez CE, Mantero F, Stowasser M, Young WF Jr \& Montori VM. Case detection, diagnosis, and treatment of patients with primary aldosteronism: an endocrine society clinical practice guideline. Journal of Clinical Endocrinology and Metabolism 200893 3266-3281. (doi:10. 1210/jc.2008-0104)

4 Ceral J, Malirova E, Kopecka P, Pelouch R \& Solar M. The effect of oral sodium loading and saline infusion on direct active renin in healthy volunteers. Acta Endocrinologica 20117 33-38. (doi:10. 4183/aeb.2011.33)

5 Solar M, Ceral J. Krajina A, Ballon M, Malirova E, Brodak M \& Cap J. Adrenal venous sampling: where is the aldosterone disappearing to? Cardiovascular and Interventional Radiology 2010 33 760-765. (doi:10.1007/s00270-009-9722-4)

6 Mulatero P, Milan A, Fallo F, Regolisti G, Pizzolo F, Fardella C, Mosso L, Marafetti L, Veglio F \& Maccario M. Comparison of confirmatory tests for the diagnosis of primary aldosteronism. Journal of Clinical Endocrinology and Metabolism 200691 2618-2623. (doi:10.1210/jc.2006-0078)

7 Loh KC, Koay ES, Khaw MC, Emmanuel SC \& Young WF Jr. Prevalence of primary aldosteronism among Asian hypertensive patients in Singapore. Journal of Clinical Endocrinology and Metabolism 200085 2854-2859. (doi:10.1210/jc.85.8.2854)

8 Stowasser M, Gordon RD, Rutherford JC, Nikwan NZ, Daunt N \& Slater GJ. Diagnosis and management of primary aldosteronism. Journal of Renin-Angiotensin-Aldosterone System 20012 156-169. (doi:10.3317/jraas.2001.022)

9 Rossi GP, Belfiore A, Bernini G, Desideri G, Fabris B, Ferri C, Giacchetti G, Letizia C, Maccario M, Mallamaci F, Mannelli M, Palumbo G, Rizzoni D, Rossi E, Agabiti-Rosei E, Pessina AC \& Mantero F. Comparison of the captopril and the saline infusion 
test for excluding aldosterone-producing adenoma. Hypertension 200750 424-431. (doi:10.1161/HYPERTENSIONAHA.107. 091827)

10 Schirpenbach C, Seiler L, Maser-Gluth C, Rudiger F, Nickel C, Beuschlein F \& Reincke M. Confirmatory testing in normokalaemic primary aldosteronism: the value of the saline infusion test and urinary aldosterone metabolites. European Journal of Endocrinology 2006154 865-873. (doi:10.1530/eje.1.02164)

11 Schirpenbach C, Seiler L, Maser-Gluth C, Beuschlein F, Reincke M \& Bidlingmaier M. Automated chemiluminescence-immunoassay for aldosterone during dynamic testing: comparison to radioimmunoassays with and without extraction steps. Clinical Chemistry 200652 1749-1755. (doi:10.1373/clinchem.2006. 068502)

Received 24 October 2011

Revised version received 3 January 2012

Accepted 17 January 2012 